\title{
Semmes Weinstein monofilaments versus Weinstein enhanced monofilaments: Their use in the hand clinic
}

\author{
MM Al-Qattan FRCSC \\ Division of Plastic Surgery, King Saud University, Riyadh, Saudi Arabia
}

\begin{abstract}
MM Al-Qattan. Semmes Weinstein monofilaments versus Weinstein enhanced monofilaments: Their use in the hand clinic. Can J Plast Surg 1995;3(1):51-53. The frequency of testing pressure threshold, the time consumed for testing, and the slippage rate using the original Semmes Weinstein monofilaments and the enhanced monofilaments (WEST) in the hand clinic are studied. A modified technique of using the WEST device is also described. It is concluded that WEST has several advantages and will likely encourage hand surgeons to perform pressure threshold testing more frequently in the clinic.
\end{abstract}

Key Words: Semmes Weinstein monofilaments, Weinstein enhanced sensory test

\section{Monofilaments de Semmes Weinstein, versus monofilaments de Weinstein améliorés : leur usage en clinique de la main}

RÉSUMÉ : La fréquence des tests de seuil de préhension, le temps consacré à l'épreuve et le taux de glissement lors de l'emploi des monofilaments de Semmes Weinstein et des monofilaments de Weinstein améliorés (WEST) en clinique de la main sont passés en revue. Une technique modifiée à l'aide du WEST est aussi décrite. La conclusion est que le WEST présente de nombreux avantages et encouragera probablement les chirurgiens de la main à effectuer des tests de préhension plus fréquemment à la clinique.

$\mathrm{I}^{\mathrm{n}}$ $\mathrm{n}$ research studies, the most commonly used quantitative tests to assess sensibility are the two-point discrimination, vibration, and pressure threshold tests $(1,2)$. However, in a busy hand clinic, the use of these quantitative tests depends upon several factors such as the availability and simplicity of the measuring device as well as the time consumed for testing.

Pressure threshold is usually measured using a set of Semmes Weinstein monofilaments (North Coast Medical Inc, San Jose, CA). After 50 years of somatosensory research, Weinstein (3) recently introduced a new modification of the original monofilament test and called it the 'Weinstein enhanced sensory test' or WEST (Connecticut Bioinstruments Inc, Danbury, CT).

In this paper, the frequency of testing pressure threshold, the time consumed for testing, and the slippage rate using the original Semmes Weinstein monofilaments (SW filaments) or the enhanced monofilaments (WEST filaments) in the hand clinic are studied.

\section{MATERIALS AND METHODS}

The SW filaments are placed individually in a box (Figure 1) and labelled with markings ranging from 1.65 to 6.65 , representing the common logarithms of the forces (expressed in

Correspondence and reprints: Dr MM AL-Qattan, PO Box 18097, Riyadh 11415, Saudi Arabia. Telephone 011-9661-464-3395, Fax 011-9661-467-9493
$0.1 \mathrm{~g})$ required to bow the filaments. The force $(\mathrm{g})$ or stress $(\mathrm{g} / \mathrm{sq} \mathrm{mm})$ of the lightest filament that evokes perception of pressure is recorded as the pressure threshold (4).

The WEST device has five enhanced monofilaments which are stacked onto one handle and placed in a protective jacket (Figure 2). For testing, each filament is employed by rotating it clear of the remaining filaments (Figure 3). Each WEST filament corresponds to a specific SW filament as shown in Table 1 .

SW and WEST filaments are applied in the same manner by keeping the filament perpendicular to the test site, slowly pressing the filament until it bends, holding it on site for about $1.5 \mathrm{~s}$, and then lifting it away from the skin (5). Slippage of the tip of the monofilament on the tested area requires the application of the filament to be repeated.

This study was performed in a hand clinic where a set of SW filaments has always been available to test hand sensibility.

More recently, WEST filaments became available for testing in the same clinic.

The first part of this study was retrospective and investigated the frequency of use of the monofilaments in two groups of patients with peripheral nerve compression or injury. Group 1 comprised 20 consecutive patients who presented to the clinic before the availability of the WEST device, and group 2 comprised 20 consecutive patients who presented after WEST became available.

In the second part of the study, three residents were introduced to the SW and WEST devices and were asked to examine 


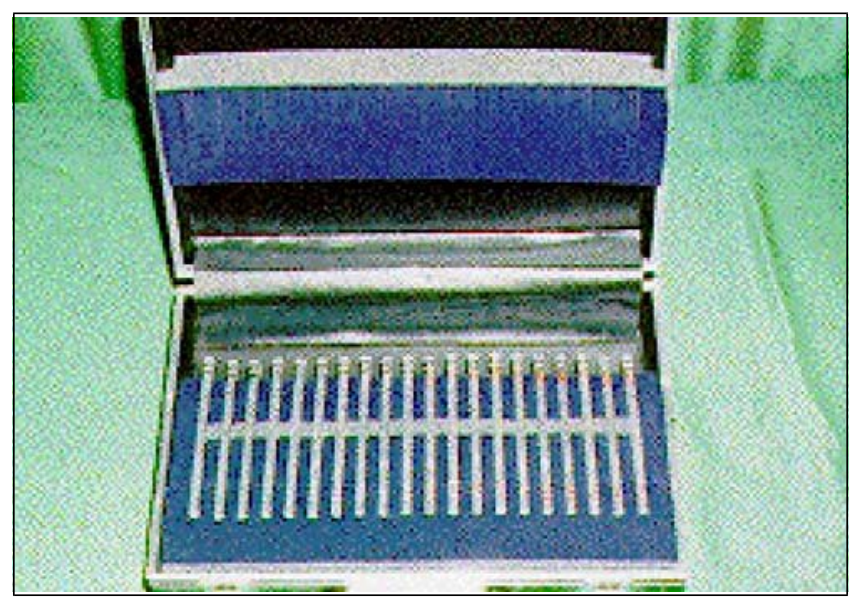

Figure 1) Semmes Weinstein (SW) filaments are placed individually in a box

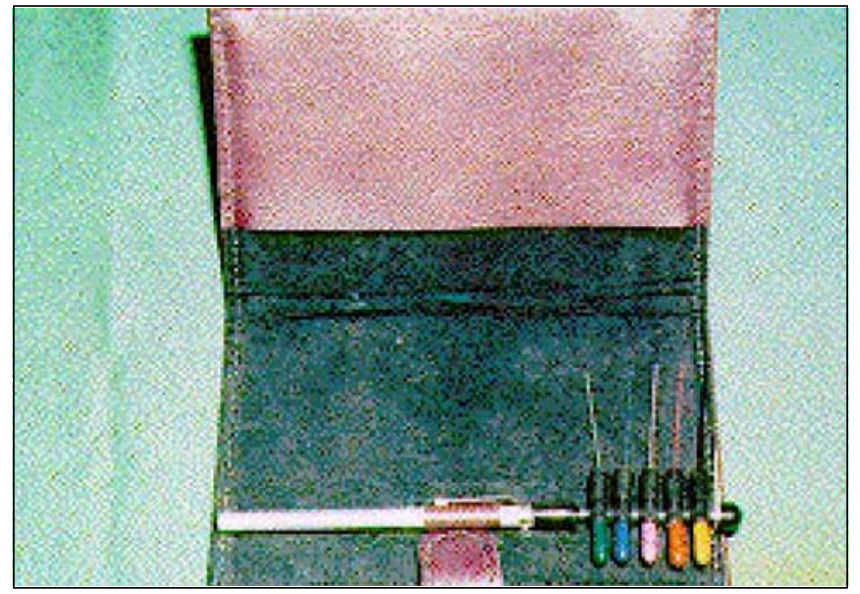

Figure 2) Weinstein enhanced (WEST) filaments are stacked onto one handle and placed in a protective jacket

10 patients with median or ulnar nerve injuries. The SW box had only five filaments to match the number of filaments in the WEST handle (Table 1). Each resident examined the pressure threshold of the pulps of the thumb and little fingers of each patient using both the SW and WEST filaments. In five patients, testing was done first with the SW device and then with WEST. The testing order was reversed in the remaining five patients. The mean time consumed for testing and the slippage rate of the tips of the monofilaments were calculated.

\section{RESULTS}

Before the availability of WEST (group 1), SW monofila- ments were used only in $10 \%$ (two of 20) patients. On the other hand, $75 \%$ (15 of 20) of patients in group 2 underwent testing of the pressure threshold using the WEST device. None of the patients in group 2 was tested using the Sw filaments which were still available in the clinic.

The mean time consumed for testing every patient was shorter using WEST ( 2 mins) than the SW filaments ( 2.3 mins). The slippage rate of the tip of the monofilaments was greater using SW filaments (10\%) than WEST filaments $(0 \%)$.

\section{DISCUSSION}

The first part of this study was retrospective and was performed because the author noticed the more frequent testing of pressure -threshold in the hand clinic after the introduction of the WEST device. The results confirmed the author's observations. There are two possible reasons to explain these results - portability of the device and the time consumed for testing. The old SW monofilaments are placed in a box while WEST can be carried in a pocket. This advantage is possibly the main reason for the more frequent use of WEST.

Weinstein (3) stated that the WEST device allows more rapid testing because filaments are only rotated for testing without the need to put each filament down carefully in the box in order to pick up a new one. The results of the second part of this study indicated that the time consumed for testing using either device was similar (a difference of $20 \mathrm{~s}$ only). This was because residents were informed (as in the manufacturer's instructions) to rotate the lever of the desired WEST filament for testing (Figure 3) without touching the filament itself. After use, the filament was rotated back to the stacked position by turning in the opposite direction. Frequently, one filament lever became lodged against another, and then the lever had to be rotated one turn in the opposite direction. All these rotations took as much time as putting in and picking out the individual SW filaments from the box.

The author has been using WEST in a different manner to shorten the time consumed for testing. Before testing, the second and fourth WEST filaments are rotated $180^{\circ}$, and hence a larger space is available between every two adjacent filament tips. In order to use filaments on each side of the handle, the handle itself is rotated instead of rotating each lever back and forth (Figure 4).

Weinstein (3) found that the percentage of slippage with the SW test on normal skin to be 5\%, whereas with the WEST it was less than $0.5 \%$. This 10 -fold reduction in slippage rate was explained by the larger surface area and increased texture of the new hemispherical tips of the enhanced filaments

TABLE 1: Interpretation of monofilament testing of pressure threshold

\begin{tabular}{lccccc}
\hline WEST monofilament number & $\mathbf{1}$ & $\mathbf{2}$ & $\mathbf{3}$ & $\mathbf{4}$ & $\mathbf{5}$ \\
\hline SW monofilament number & 2.83 & 3.61 & 4.31 & 4.56 & 4.65 \\
Force $(\mathrm{g})$ & 0.07 & 0.2 & 2 & 4 & 200 \\
Interpretation of threshold & Normal sensibility & $\begin{array}{c}\text { Reduced tactile } \\
\text { sensation }\end{array}$ & $\begin{array}{c}\text { Reduced protective } \\
\text { sensation }\end{array}$ & $\begin{array}{c}\text { Loss of protective } \\
\text { sensation }\end{array}$ & \begin{tabular}{c} 
Residual sensation \\
\hline
\end{tabular} \\
\hline
\end{tabular}




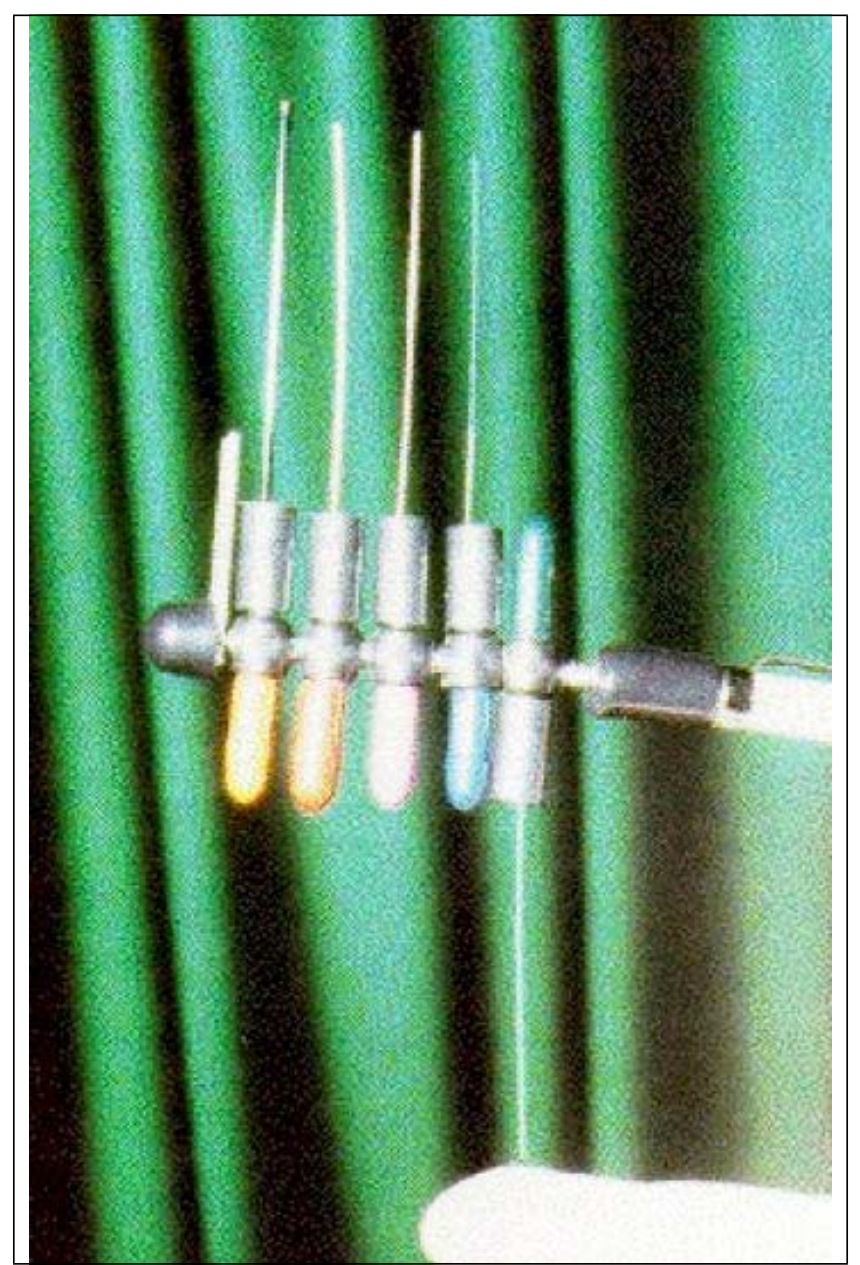

Figure 3) Testing using the WEST device as recommended by the manufacturer. The desired filament is employed by rotating it clear of the remaining filaments

(SW filaments have flat circle tips). In our study, the higher slippage rate (10\%) using the SW filaments could be explained by the fact that testing in our clinic was done on smooth denervated skin in patients with nerve injuries.

In a recent communication (6), the inventors of the WEST device mentioned another advantage of the enhanced tips. When the hemispherical tip of the WEST filament is applied, the contacting surface remains basically a hemisphere, whereas when the SW filament is applied, the tip in contact

\section{REFERENCES}

1. Posnick JC, Al-Qattan MM, Pron GE, Grossman JAI. Facial sensibility in adolescents born with cleft lip after undergoing repair in infancy. Plast Reconstr Surg 1994;93:682-5.

2. Posnick JC, Al-Qattan MM, Pron GE. Facial sensibility in adolescents with and without clefts 1 year after undergoing Le Fort I osteotomy. Plast Reconstr Surg 1994;94:431-5.

3. Weinstein S. Fifty years of somatosensory research: From the Semmes-Weinstein Monofilaments to the Weinstein Enhanced Sensory test. J Hand Ther 1993;6:11-22.

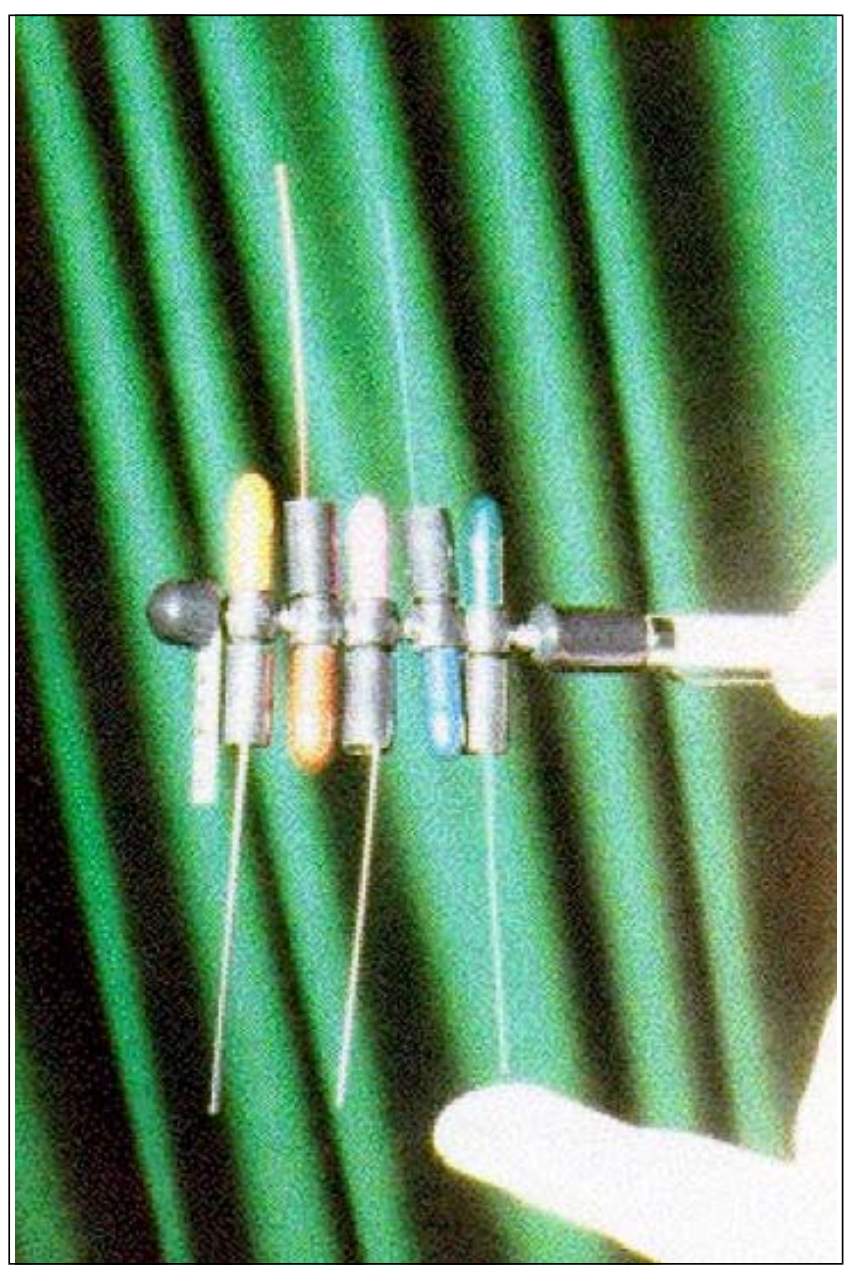

Figure 4) Testing using the WEST device as suggested by the author. Before testing the second and fourth WEST filaments are rotated $180^{\circ}$, and hence a larger space is available between every two adjacent filament tips. During testing, the whole handle is rotated instead of rotating each individual lever back and forth

with the skin is first a flat circle and, upon bending the filament, the contacting tip may become a sharp crescent. Thus, when using the SW filaments, the pressure calculated is only apparent, because the contacting face varies during stimulation.

In conclusion, WEST has several advantages when compared with the old SW filaments and will likely encourage hand surgeons to perform pressure threshold testing more frequently in the clinic.

4. Levin S, Pearsall G, Ruderman RJ. Von Frey's method of measuring pressure sensibility in the hand: An engineering analysis of the Weinstein-Semmes pressure aesthesiometer. J Hand Surg 1978;3:211-6.

5. Bell-Krotoski JA, Buford Jr WL. The force/time relationship ofclinically used sensory testing instruments. J Hand Ther 1988;1:76-85.

6. Weinstein S, Weinstein C, Drozdenko R. Discussion: facial sensibility in adolescents born with cleft lip after undergoing repair in infancy. Plast Reconstr Surg 1994;93:686-9. 